\title{
Detection of Apoptosis in Kidney Biopsies of Patients with D+ Hemolytic Uremic Syndrome
}

\author{
D. MAROESKA W.M. TE LOO, LEO A.H. MONNENS, LAMBERTUS P.W.J. VAN DEN HEUVEL, \\ MARIE C. GUBLER, AND MARK M. KOCKX
}

\begin{abstract}
Department of Pediatrics, University Hospital Nijmegen, Nijmegen, the Netherlands [D.M.W.M.T., L.A.H.M., L.P.W.J.V.]; Inserm U 423, Hôspital Necker-Enfants Malades, Paris, France [M.C.G.]; Department of Pathology, University of Antwerp, AZ-Middelheim, Antwerp, Belgium [M.M.K.]
\end{abstract}

\begin{abstract}
In this study we have investigated the presence of apoptotic cells in renal biopsy material of seven patients with hemolytic uremic syndrome (HUS) by using an improved and stringent terminal deoxynucleotidyl nick-end labeling (TUNEL) technique. Renal biopsy material was taken in the second or third week after onset of the disease. Renal biopsy material of patients with minimal lesions nephrotic syndrome or thin basement syndrome were used as control. It has been reported that nonapoptotic cells can be labeled nonspecifically due to proteinase $\mathrm{K}$ pretreatment or a delay in fixation when only TUNEL technique is used. In post mortem material this delay in fixation is seen. Moreover, it has been described that mainly nonapoptotic cells that shows signs of active gene transcription can be labeled in this nonspecific way. For this reason we used the TUNEL technique in combination with a label for RNA synthesis and splicing factor (SC-35). Indeed, we found nonspecific labeling of nonapoptotic nuclei in biopsy material of HUS patients, but not in control biopsy material. By using co-labeling with RNA
\end{abstract}

\section{ABSTRACT}

synthesis factor SC-35, we were able to identify true apoptotic cells. There was a significant increase $(p<0.05)$ in the presence of apoptotic cells in biopsy material of HUS patients compared with material of controls. About $80 \%$ of apoptotic cells were detected in tubuli and only $20 \%$ in glomeruli of the renal biopsies of HUS patients. Furthermore, most apoptotic cells were detected in those patients that had received peritoneal dialysis suggesting that there is a relationship between severity of the disease and amount of apoptotic cells. The finding of apoptotic cells suggest that apoptosis plays a role in HUS. (Pediatr Res 49: 413-416, 2001)

Abbreviations
D+ HUS, diarrhea-associated hemolytic uremic syndrome
VT, verocytotoxin
Gb3, globotriaosylceramide receptor
TUNEL, terminal deoxynucleotidyl nick-end labeling
TMA, thrombotic microangiopathy

The HUS is the most common cause of acute renal failure in children. Infection with a VT-producing Escherichia coli has been strongly implicated in the epidemic form (D+) of HUS (1). The pathogenesis of HUS is hallmarked by endothelial damage of glomeruli and arterioles of the kidney. In severe cases, other organs such as brain and pancreas are involved (2).

The mechanism by which VT causes cell damage is not clear. In vitro studies have shown that VT can bind specific to the Gb3 present on endothelial cells $(3,4)$. After binding, VT enters the cell and causes inhibition of overall protein synthesis through the enzymatic inactivation of the $60 \mathrm{~S}$ ribosomal unit and thereby leading to cell death (5).

Apoptosis, or programmed cell death, is characterized by series of ultrastructural morphologic changes such as cell shrinkage, membrane blebbing, and condensation of the nuclear chromatin (6). These morphologic changes are accompa-

Correspondence: L.A.H. Monnens, MD, University Hospital Nijmegen, Department of Pediatric Nephrology, 6500 HB Nijmegen, The Netherlands.

Supported by grant 97.1645 from the Dutch Kidney Foundation. nied by fragmentation of nuclear DNA into multiples of $185 \mathrm{bp}$ resulting in a characteristic DNA ladder pattern on electrophoresis $(7,8)$. This form of cell death is a normal physiologic process by which an organism removes damaged or unnecessary cells (9). However, apoptosis can also be induced by a diverse array of external triggers such as ionizing radiation or infection with a variety of toxins (10). In vitro experiments by our group showed that VT induces apoptosis in tumor necrosis factor (TNF)- $\alpha$-stimulated glomerular microvascular endothelial cells (11). Recently, apoptosis in autopsy material of two children and biopsy material of one child with the epidemic form of HUS has been described (12). Apoptotic cells were identified using the terminal deoxynucleotidyl transferasemediated dUTP nick-end labeling technique, also called TUNEL technique. This technique is often used to study apoptosis. A serious drawback of the TUNEL technique is that nuclei can be labeled nonspecifically due to the proteinase $\mathrm{K}$ pretreatment or delay in tissue fixation. Recently, it was demonstrated that mainly nonapoptotic cells that show signs of active gene transcription can be labeled by the TUNEL tech- 
nique in an nonspecific way (13). The nonapoptotic cells are still active and are transcribing genes that might be related or completely unrelated to the apoptotic cell death pathway. In a true apoptotic cell the nuclear DNA is cleaved in oligonucleosomal-sized fragments and processes like DNA repair and RNA transcription/splicing are abolished. Moreover, even in the early execution phase of apoptosis, caspase 3 cleaves DNA repair enzymes like PARP (14), DNA-PKcs (15), and the 70 $\mathrm{kD}$ protein complement of splicing factor U1 snRP (16). The loss of RNA splicing can be considered as an early step in the execution phase of apoptosis. In the present study we have combined the TUNEL technique with a marker of RNA splicing (17). True apoptotic nuclei will be TUNEL positive but RNA splicing negative, whereas nonapoptotic TUNEL positive cells will be RNA splicing factor positive. This combined TUNEL technique was applied to renal biopsies of seven patients with HUS (acute phase) versus seven patients with either minimal change or thin basement syndrome to study whether apoptosis plays a role in HUS.

\section{PATIENTS AND METHODS}

Renal biopsy material of seven patients in the acute phase of HUS was used to investigate the presence of apoptosis. The study has been approved by the applicable institutional review board. Clinical characteristics of the patients are shown in Table 1. Light microscopy of the patients with HUS showed characteristic lesions of glomerular TMA. They involved $10 \%$ of glomeruli in patient 2 and $50 \%-60 \%$ of glomeruli in the others. Typical glomeruli were enlarged and showed thickening of the capillary walls with a double contour appearance due to widening of the subendothelial space. Endothelial cells were frequently swollen. Mesangial areas were enlarged with a fibrillar appearance of the mesangial matrix. In less severely affected glomeruli, the only change was a fibrillar widening of mesangial areas. Arteriolar changes were discrete in all patients and characterized by an irregular widening of the subendothelial space. By immunofluorescence microscopy, deposits of fibrin along glomerular capillary walls were observed in five patients (patients 2, 3, 5, 6, and 7). Biopsy material of patients with either minimal lesions nephrotic syndrome (MLS) or thin basement membrane syndrome (TBM) were used as control. All material was paraffin embedded.

TUNEL-labeling combined with immunohistochemical staining for RNA splicing. All biopsy material was first deparaffinized and rehydrated. Subsequently, material was incubated with $3 \%$ citric acid to remove all small calcium-containing vesicles that could be responsible for nonspecific binding (17).

For the TUNEL technique (13), sections were incubated for $1 \mathrm{~h}$ at $37^{\circ} \mathrm{C}$ in a solution containing $25 \mathrm{mM}$ Tris pH 6.6, 200 $\mathrm{mM}$ sodium cacodylate, $1.25 \mathrm{mg} / \mathrm{mL}$ BSA, $1.25 \mathrm{mM} \mathrm{CoCl}_{2}, 10$ $\mu \mathrm{M}$ dATP (Sigma Chemical Co., Poole, U.K.), $2.5 \mu \mathrm{M}$ fluorescein-dUTP (Amersham, Little Chalfont, U.K.), $50 \mathrm{U} / \mathrm{mL}$ TdT (Boehringer Mannheim, Mannheim, Germany). Incorporated fluorescein-dUTP was demonstrated with a sheep antifluorescein peroxidase-conjugated antiserum (Boerhinger Mannheim) at a dilution of $1 / 300$ for $45 \mathrm{~min}$. The labeled antibody was visualized by aminoethylcarbazole (AEC). Sections were lightly counterstained with hematoxylin and mounted in glycerin jelly.

Sections stained with the TUNEL technique were subsequently stained for splicing factor (splicing component SC-35) (13). The TUNEL-stained sections were incubated with a mouse MAb against splicing factor (Sigma Chemical Co.) used at a dilution of $1 / 200$ and visualized by a goat anti-mouse alkaline phosphatase antibody. Fast blue was used as a chromogen.

\section{RESULTS}

Renal biopsy material of seven HUS patients seemed to show a significant amount of apoptotic cells (about 30\%) after staining with TUNEL technique alone (Fig. 1A). However, staining with RNA splicing factor showed that most of the cells positive with the TUNEL technique were also positive for RNA splicing activity, indicating that these cells were not in the execution phase of the apoptotic process. (Fig. 1B). The numbers of apoptotic cells were counted in five different glomeruli and surrounding tubuli in each patient and total number of apoptotic cells are shown in Table 2. Co-labeling showed that just $2.5 \%$ of the cells $(1.5 \%$ located in tubules) stained with the TUNEL technique were indeed apoptotic (Fig. $1, C-F$ ). However, even after co-labeling the sections (TUNEL and SC-35), renal biopsy material of HUS patients showed a significant increase (Wilcoxon test: $p<0.05$ ) in apoptotic cells in glomeruli and tubuli compared with controls (Table 2). Interestingly, the amount of apoptotic cells detected in tubuli of HUS patients was significantly higher ( $30 \%$ of total apoptotic cells) than those detected in the glomeruli. Furthermore, a much stronger positive staining for RNA splicing factor in the tubular epithelial cells was found in patients with HUS compared with controls (Fig. 1), indicating that there was a higher transcription activity in HUS patients.

Table 1. Clinical characteristics of HUS patients

\begin{tabular}{|c|c|c|c|c|c|c|c|c|}
\hline $\begin{array}{l}\text { Patient } \\
\text { no. }\end{array}$ & Age (mo) & Diarrhea & $\begin{array}{c}\text { Thrombocytes } \\
\left(\times 10^{9} / \mathrm{L}\right)\end{array}$ & Anuria & $\begin{array}{l}\text { Creatinine } \\
(\mu \mathrm{mol} / \mathrm{L})\end{array}$ & Dialysis & $\begin{array}{l}\text { Time of } \\
\text { biopsy* }\end{array}$ & $\begin{array}{l}\text { Affected } \\
\text { glomeruli }\end{array}$ \\
\hline 1 & 18 & + & 30 & - & 130 & - & 19 & $50 \%$ \\
\hline 2 & 11 & + & 26 & - & 264 & - & 16 & $10 \%$ \\
\hline 3 & 9 & + & 8 & $8 \mathrm{~d}$ & 123 & + & 15 & $65 \%$ \\
\hline 4 & 18 & + & 58 & $7 \mathrm{~d}$ & 378 & - & 12 & $70 \%$ \\
\hline 5 & 15 & + & 59 & $8 \mathrm{~d}$ & 476 & + & 8 & $65 \%$ \\
\hline 6 & 36 & + & 50 & $5 \mathrm{~d}$ & 600 & + & 14 & $60 \%$ \\
\hline 7 & 23 & + & 40 & - & 780 & + & 18 & $50 \%$ \\
\hline
\end{tabular}

* The time of biopsy is expressed in days after the patient was diagnosed as having HUS. 

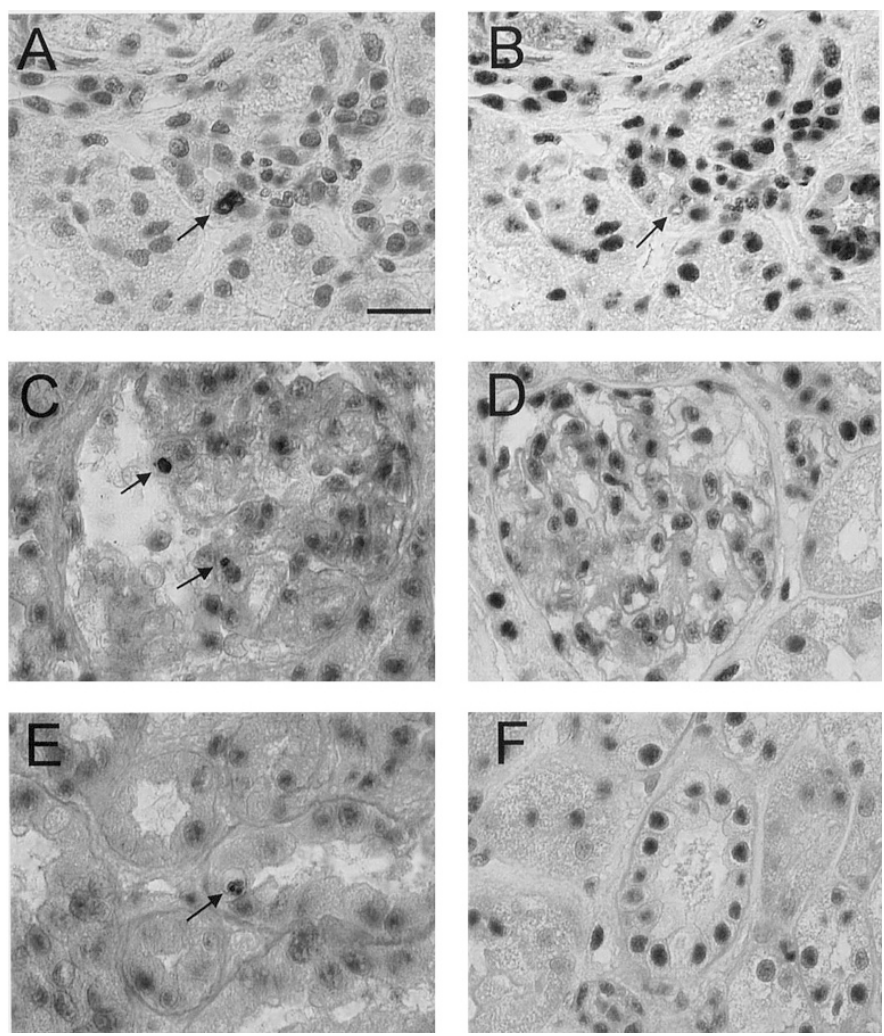

Figure 1. Detection of apoptosis in renal biopsies in D+ HUS patients $v s$ controls. (A) Labeling with TUNEL technique and SC-35 nuclei that show high levels of RNA synthesis/splicing are stained in blue, which will mask the nonspecific (brown) signal of the TUNEL technique. Only one cell is really apoptotic (indicated with an arrow). (B) The same section of $A$ is shown, however the material was washed out and labeled again with SC-35 alone (brown this time): A tubulus and a part of a glomerulus are shown. Numerous nuclei of the tubulus and the glomerulus are labeled (brown-labeled nuclei). The cell positive for apoptosis in $A$ after staining with the TUNEL technique and labeling with SC-35, shows in $B$ no positive staining at all, indicating that this cell has no RNA synthesis/splicing activity and is really apoptotic. All the other cells have high RNA synthesis/splicing activity and are therefore not apoptotic. (C) Double labeling of TUNEL and SC-35. A glomerulus of a HUS patient contains two TUNEL-positive nuclei that are negative for SC-35, which indicates the presence of apoptosis in the glomerulus. $(D)$ Double labeling of TUNEL and SC-35. A glomerulus of a control patient is shown without apoptosis The nuclei show signs of RNA synthesis/splicing. (E) Double labeling of TUNEL and SC-35. A tubulus of a HUS patient that contains TUNEL-positive nucleus that is negative for SC-35, which indicates apoptosis in the tubular epithelial cells of this HUS patient. $(F)$ Double labeling of TUNEL and SC-35. A tubulus of a control patient is demonstrated without apoptosis.

Clinical characteristics of patients are shown in Table 1. All patients had a prodromal phase of bloody diarrhea. Interestingly, those patients who were treated with dialysis (patients 3-6) had more apoptotic cells than patients that received no dialysis, suggesting that there might be a relationship between severity of the disease and amount of apoptotic cells detected. Finding of apoptotic cells suggest that apoptosis plays a role in the pathogenesis of HUS.

\section{DISCUSSION}

In this study we used an improved and stringent TUNEL technique to detect apoptotic cells in renal biopsies. We investigated renal biopsy material of seven D + HUS patients and
Table 2. Number of apoptotic cells detected in five different glomeruli and surrounding tubuli in each biopsy of HUS patients and controls

\begin{tabular}{cccc}
\hline Patient no. & Glomeruli & Tubuli & Total \\
\hline 1 & 0 & 3 & 3 \\
2 & 1 & 0 & 1 \\
3 & 1 & 7 & 8 \\
4 & 2 & 4 & 6 \\
5 & 2 & 6 & 8 \\
6 & 0 & 7 & 7 \\
7 & 0 & 1 & 1 \\
MLS & 0 & 0 & 0 \\
MLS & 0 & 0 & 0 \\
TBM & 0 & 0 & 0 \\
TBM & 0 & 0 & 0 \\
TBM & 0 & 0 & 0 \\
TBM & 0 & 1 & 1 \\
TBM & 0 & 0 & 0 \\
\hline
\end{tabular}

For statistical analysis, Wilcoxon test was used. There was a significant increase of apoptotic cells in patients with HUS compared with controls $(p<$ 0.05 ). Eighty percent of apoptotic cells observed in HUS patients were localized in the tubuli and only $20 \%$ in glomeruli.

MLS, minimal lesions nephrotic syndrome; TBM, thin basement membrane.

found an increased number of apoptotic cells in glomeruli and tubuli compared with control patients with minimal lesions nephrotic syndrome or thin basement syndrome.

Endothelial damage of primarily glomeruli is a characteristic feature of HUS. Although a lot of the pathogenesis of HUS remains unclear, it has been postulated that VT plays an important role in the damage of endothelial cells of glomeruli and to a lesser extent renal arterioles $(2,18)$. In several studies, a role of VT in inducing apoptosis has been suggested $(19,20)$. In vitro experiments have shown that $\mathrm{VT}$ binds to the $\mathrm{Gb} 3$ receptor found after stimulation on endothelial cells, enters the cell, and can cause inhibition of overall protein synthesis $(3,4)$. In vitro studies performed with Vero-, Burkitt's lymphoma, and renal tubular epithelial cells have shown that VT can induce apoptosis $(19,21,22,23)$. Experiments performed in our own group demonstrated that VT can also induce apoptosis in human glomerular endothelial cells in vitro by a mechanism that involves caspase 3 (11). Mitra et al. described that plasma of patients with thrombotic thrombocytopenic purpura, a disease that is closely related to HUS, can induce apoptosis in restricted lineages of human microvascular endothelial cells (24). Furthermore, it has been described that endothelial cells undergoing apoptosis become procoagulant and proadhesive for platelets (25).

The finding of apoptotic cells in HUS patients in vivo using a double labeling for RNA syntheses splicing factor (SC-35) together with the TUNEL-technique has not been described before. In a recent study, the presence of apoptosis was studied in biopsy material of one child and in postmortem tissue of two children with D+ HUS (12). Apoptotic cells were detected in tubular structures and in lesser extent in glomeruli of the kidney. TUNEL technique was used to identify apoptotic cells. However, it has been reported that different factors such as RNA synthesis/splicing and small calcium containing vesicles can interfere with TUNEL labeling $(13,17)$.

In this study of biopsy material of seven HUS patients we demonstrate that there is indeed nonspecific labeling of non- 
apoptotic cells in biopsy material by the TUNEL reaction. Therefore we used a co-labeling for RNA synthesis splicing factor and incubated the material of patients and controls with citric acid to remove calcium-containing vesicles. RNA transcription and splicing requires intact DNA indicating that cells positive for both TUNEL and RNA-splicing factor probably are not apoptotic. Sections of renal biopsy material of HUS patients stained with TUNEL showed a high fraction of nuclei that were labeled $(30 \%)$ mainly in tubuli and in lesser extent glomeruli. Correction for RNA splicing factor made it possible to differentiate between TUNEL false-positive cells and to identify true apoptotic cells. Especially nonapoptotic nuclei showing signs of active gene transcription can be labeled nonspecific by the TUNEL technique. Renal epithelial cells show high levels of RNA synthesis and therefore are prone for this nonspecific labeling in the TUNEL technique. However, we still found an increased number of apoptotic cells in HUS patients compared with controls, indicating that apoptosis probably plays a role in HUS. It is even possible that there is an underestimation of the amount of apoptosis, because all biopsy material we used was taken in the second week of the disease or even later and patients might be already recovering at that time. Normally, apoptotic cells are removed by macrophages in just a few hours $(9,26)$.

In addition to finding apoptosis, we observed an increased RNA splicing activity in biopsy material of HUS patients compared with controls. This indicates that cells were active and transcribing genes that might be related or completely unrelated to the apoptotic process. Because the induction of apoptosis normally does not require new protein synthesis, it is more reasonable to think that high RNA synthesis and splicing activity is not related to the apoptotic process. It is even possible that the high RNA synthesis and splicing activity is related to a phase of repair and re-establishment (27). Furthermore, we found that most apoptotic cells were seen in those patients who were anuric or who received peritoneal dialysis, suggesting that there is a relationship between seriousness of the disease and amount of apoptotic cells.

In conclusion, we demonstrated the presence of apoptotic cells in glomeruli and tubuli of renal biopsy material of HUS patients. The finding of apoptotic cells suggests that apoptosis plays a role in HUS. Probably more apoptosis will be seen at an early point of time in the course of the disease.

\section{REFERENCES}

1. Karmali MA, Petric M, Lim C, Fleming PC, Arbus GS, Lior H 1985 The association between idiopathic hemolytic uremic syndrome and infection by verotoxin-producing Escherichia coli. J Infect Dis 151:775-782
2. Fong JS, de Chadarevian JP, Kaplan BS 1982 Hemolytic-uremic syndrome. Current concepts and management. Pediatr Clin North Am 29:835-856

3. van de Kar NC, Monnens LA, Karmali MA, van Hinsbergh VW 1992 Tumor necrosis factor and interleukin-1 induce expression of the verocytotoxin receptor globotriaosylceramide on human endothelial cells: implications for the pathogenesis of the hemolytic uremic syndrome. Blood 80:2755-2764

4. van Setten PA, van Hinsbergh VW, van der Velden TJ, van de Kar NCAJ, Vermeer M, Mahan JD, Assman KJM, van den Heuvel LPWJ, Monnens LAH 1997 Effects of TNF alpha on verocytotoxin cytotoxicity in purified human glomerular microvascular endothelial cells. Kidney Int 51:1245-1256

5. Sandvig K, van Deurs B 1996 Endocytosis, intracellular transport, and cytotoxic action of Shiga toxin and ricin. Physiol Rev 76:949-966

6. Wyllie AH 1997 Apoptosis: an overview. Br Med Bull 53:451-465

7. Kroemer G, Petit P, Zamzami N, Vayssiere JL, Mignotte B 1995 The biochemistry of programmed cell death. FASEB J 9:1277-1287

8. Majno G, Joris I 1995 Apoptosis, oncosis, and necrosis. An overview of cell death. Am J Pathol 146:3-15

9. Hockenbery D 1995 Defining apoptosis. Am J Pathol 146:16-19

10. Allam M, Bertrand R, Zhang-Sun G, Pappas J, Viallet J 1997 Cholera toxin triggers apoptosis in human lung cancer cell lines. Cancer Res 57:2615-2618

11. Pijpers AJHM, van Setten PA, van den Heuvel LPWJ, Assmann KJM, Dijkman HBPM, Pennings AHM, Monnens LAH, van Hinsbergh VWM 2000 Verocytotoxin induced apoptosis in human microvascular endothelial cells. J Am Soc Nephrol (in press)

12. Karpman D, Hakansson A, Perez MT, Isaksson C, Carlemalm E, Caprioli A, Svanborg C 1998: Apoptosis of renal cortical cells in the hemolytic-uremic syndrome: in vivo and in vitro studies. Infect Immun 66:636-644

13. Kockx MM, Muhring J, Bortier H, de Meyer GR, Jacob W 1996 Biotin- or digoxigenin-conjugated nucleotides bind to matrix vesicles in atherosclerotic plaques. Am J Pathol 148:1771-1777

14. Tewari M, Quan LT, O'Rourke K, Desnoyers S, Zeng Z, Beidler DR, Poirier GG, Salvesen GS, Dixit VM 1995 Yama/CPP32 beta, a mammalian homolog of CED-3, is a CrmA-inhibitable protease that cleaves the death substrate poly(ADP-ribose) polymerase. Cell 81:801-809

15. Song Q, Lees-Miller SP, Kumar S Zhang Z, Chan DW, Smith GC, Jackson SP, Alnemri ES, Litwack G, Khanna KK, Lavin MF 1996 DNA-dependent protein kinase catalytic subunit: a target for an ICE-like protease in apoptosis. EMBO J 15:32383246

16. Casciola-Rosen LA, Miller DK, Anhalt GJ, Rosen A 1994 Specific cleavage of the $70-\mathrm{kDa}$ protein component of the U1 small nuclear ribonucleoprotein is a characteristic biochemical feature of apoptotic cell death. J Biol Chem 269:30757-30760

17. Kockx MM, Muhring J, Knaapen MW, de Meyer GR 1998 RNA synthesis and splicing interferes with DNA in situ end labeling techniques used to detect apoptosis. Am J Pathol 152:885-888

18. Kavi J, Chant I, Maris M, Rose PE 1987: Cytopathic effect of verotoxin on endothelial cells. Lancet 2:1035

19. Kiyokawa N, Taguchi T, Mori T, et al 1998 Induction of apoptosis in normal human renal tubular epithelial cells by Escherichia coli Shiga toxins 1 and 2. J Infect Dis 178:178-184

20. Taga S, Carlier K, Mishal Z, Capoulade C, Mangeney M, Lecluse Y, Coulaud D, Tetaud C, Pritchard LL, Tursz T, Wiels J 1997 Intracellular signaling events in CD77-mediated apoptosis of Burkitt's lymphoma cells. Blood 90:2757-2767

21. Inward CD, Williams J, Chant I, Crocker J, Milford DV, Rose PE, Taylor CM 1995 Verocytotoxin-1 induces apoptosis in vero cells. J Infect 30:213-218

22. Mangeney M, Lingwood CA, Taga S, Caillou B, Tursz T, Wiels J 1993 Apoptosis induced in Burkitt's lymphoma cells via Gb3/CD77, a glycolipid antigen. Cancer Res 53:5314-5319

23. Taguchi T, Uchida H, Kiyokawa N, Mori T, Sato N, Horie H, Takeda T, Fujimoto J 1998: Verotoxins induce apoptosis in human renal tubular epithelium derived cells. Kidney Int 53:1681-1688

24. Mitra D, Jaffe EA, Weksler B, Soderland C, Laurence J 1997 Thrombotic thrombocytopenic purpura and sporadic hemolytic-uremic syndrome plasmas induce apoptosis in restricted lineages of human microvascular endothelial cells. Blood 89:12241234

25. Bombeli T, Schwarts BR, Harlan J M 1999 Endothelial cells undergoing apoptosis become proadhesive for nonactivated platelets. Blood 93:3831-3838

26. Bright j, KharJ, Khar A 1994 Apoptosis: programmed cell death in health and disease. Biosci Rep 14:67-81

27. Kanoh M, Takemura G, Misao J, Hayakawa Y, Aoyama T, Nishigaki K, Noda T, Fujiwara T, Fukuda K, Minatoguchi S, Fujiwara H 1999: Significance of myocytes with positive DNA in situ nick end-labeling (TUNEL) in hearts with dilated cardiomyopathy: not apoptosis but DNA repair. Circulation 99:2757-2764 